\title{
Autotransplantation of parathyroid grafts into the tibialis anterior muscle after parathyroidectomy: a novel autotransplantation site
}

\author{
Chrysanthi Anamaterou', Matthias Lang', Simon Schimmack², Gottfried Rudofsky ${ }^{3}$, Markus W. Büchler ${ }^{2}$ \\ and Hubertus Schmitz-Winnentha $2^{2^{*}}$
}

\begin{abstract}
Background: Surgical management of renal secondary hyperparathyroidism (SHPT) is varying. Total parathyroidectomy with heterotopic autotransplantation (TPTX + AT) is one of the standard surgical procedures in SHPT, but there is no consensus about the optimal site for graft insertion. At the surgical department of the University Hospital of Heidelberg we prefer the autotransplantation into the tibialis anterior muscle. The aim of this study was to assess the long-term function of the auto-transplanted parathyroid tissue in this type of surgical procedure.

Methods: The function of the autograft of 42 patients was assessed $8.2 \pm 2.5$ years after surgery, using a modified Casanova-test of the leg bearing the parathyroid tissue. Ischemic blockage was induced by tourniquet and the levels of parathyroid hormone (PTH) were assessed during the test.

Results: At the point of assessment, the ischemic blockage led to a significant reduction in the concentration of PTH ( $\geq 50 \%$ of the baseline value) in 19 patients ( $45 \%$ ) indicating well-functioning autografts. In 11 patients ( $26 \%$ ), ischemic blockage did not cause any change in the concentration of PTH ( $\leq 20 \%$ of the baseline value), indicating functioning residual parathyroid tissue from another site. The source of PTH production was classified as unidentifiable in five patients (12\%). Two patients had developed graft-dependent recurrent HPT (5\%) without therapeutic consequences and three patients suffered from persistent symptomatic hypoparathyroidism (7 \%).

Conclusions: These results indicate that TPTX + AT into the tibialis anterior muscle is a successful surgical treatment for renal HPT and that the modified Casanova-test is a suitable diagnostic tool for autografts function.
\end{abstract}

Keywords: Renal hyperparathyroidism, Parathyroidectomy, Autotransplantation, Casanova-test

\section{Background}

Secondary hyperparathyroidism (sHPT) is a frequent complication of chronic renal insufficiency (CRI), especially end-stage renal disease (ESRD) [1,2]. Advances in the medical treatment of sHPT have reduced the need for surgery, however 5-10 \% of patients still require parathyroidectomy [2-4]. Surgical management of sHPT is varying $[2,3]$. It can be performed using either subtotal parathyroidectomy or total parathyroidectomy (TPTX) with or without autotransplantation (AT) $[2,3,5,6]$. AT of parathyroid grafts into the sternocleidomastoid muscle

\footnotetext{
* Correspondence: winnenthal@googlemail.com

${ }^{2}$ Department of General, Visceral and Transplantation Surgery, University of Heidelberg, Im Neuenheimer Feld 110, 69120 Heidelberg, Germany Full list of author information is available at the end of the article
}

$[7,8]$ or the subcutaneous abdominal adipose tissue have been widely used [9], however Wells et al. have demonstrated that the forearm muscle can be more advantageous [10-12]. Subcutaneous pre-sternal transplantation [13], subcutaneous injection or transplantation in the forearm $[14,15]$ and intramuscular injection in the deltoid [16], have also been described.

At the University Hospital of Heidelberg, the preferred method is TPTX with AT of half of the parathyroid gland into the (right) tibialis anterior muscle. This is to preserve the forearm if any additional shunt replacement and/or revision in patients with SHPT become necessary. This method also allows further surgeries under local anesthesia when recurrent graft-dependent HPT appears $[2,6]$. Furthermore the function of the remnant can be 
observed by a Casanova-test; which is not the case for in patients with remnants in the neck or abdominal wall $[17,18]$. The effectiveness of this method, particularly with respect to the location of $\mathrm{AT}$, has yet to be described.

The Casanova-test was developed to establish graft dependent recurrence $[17,19]$. A simplified version of the test, without intravenous regional analgesia (SCAT), has been shown to distinguish the site of recurrence in $90 \%$ of patients, when comparing to the measurement of parathyroid hormone (PTH) levels at 10 min of suprasystolic exclusion of the grafted arm to preischemic values [18].

Currently, there is no accepted standard for either the optimal site of AT or for defining a fully functional autograft. The objective of this study is to evaluate the feasibility of the new AT site and determine the function of the parathyroid autografts by means of the modified Casanova-test.

\section{Methods}

\section{Study design and study population}

Between 2002 and 2010, AT of parathyroid tissue into the tibialis anterior muscle was the standard approach applied in renal patients who were undergoing parathyroidectomy at the University Hospital of General, Visceral and Transplantation Surgery of Heidelberg, Germany. Forty-two patients after TPTX with AT into the tibialis anterior muscle were retrospectively examined on average $8.2 \pm$ 2.5 years after surgery. Patients with primary hyperparathyroidism or recurrent/ persistent disease and patients under 18 years of age were not considered for enrollment. The study population consisted of 26 men (mean age $50.5 \pm 12.4$ years) and 16 women (mean age $56.1 \pm$ 11.6 years). Until surgery all patients received maximum conservative therapy (vitamin D and/or analogues and phosphate binders) and only five patients received calcimimetic agents (cinacalcet). At presentation one third of the patients were still on dialysis. Written informed consent for participation in the study and publication of acquired data was obtained from all study patients. Ethics approval was provided by the ethics committee of the medical faculty of the University of Heidelberg (Ethics Approval Number S-169/2011).

\section{Surgical procedure}

After removal of all identified parathyroid glands, half of the smallest $(0,2-0,5 \mathrm{~cm})$ and most physiological -not hyperplastic- appearing gland was carefully comminuted into $1 \mathrm{~mm}$-thick pieces. After incision in the right lower leg $(2 \mathrm{~cm})$, an avascular pocket was created in the tibialis anterior muscle and the pieces of the parathyroid gland were implanted in all 42 patients, marked with a clip, and the muscle pocket was closed with a suture.
Additional cervical thymectomy was performed in 13 patients (total or partial); total or subtotal thyroidectomy in five patients and both in one patient. Final histology reports revealed the presence of four parathyroid glands in 36 patients $(86 \%)$, three glands in five patients and two glands in one patient. The most common complication was mild postoperative hypocalcemia (mean $1.90 \pm$ $0.15 \mathrm{mmol} / \mathrm{l}$ ) in 22 patients (52\%). Other complications observed included hungry-bone syndrome (three patients, $7 \%$ ), hyperthyroidism (two patients, $5 \%$ ), and transient partial recurrent laryngeal nerve palsy (two patients, $5 \%$ ).

\section{Casanova-test}

Modified Casanova-test was performed as previously described [17-19]. A Visomat comfort Typ 2040 blood pressure cuff (UEBE Medical GmbH, Wertheim, Germany) was used to measure systemic blood pressure at the left upper arm. After padding the right upper leg with cotton wool, a pneumatic tourniquet (Welch Allyn large adult Nr.12 durable blood pressure cuff or ERKA perfect aneroid extra large cuff) was placed. The tourniquet was inflated between 30 and $50 \mathrm{mmHg}$ over the systolic blood pressure. Lack of pulse of the lower limb was assessed. Ischemia of the lower limb was maintained for $15 \mathrm{~min}$. Blood samples were obtained from the arm before the ischemic period, during the ischemic period (at 5; 10; $15 \mathrm{~min}$ ) and $10 \mathrm{~min}$ after deflating the tourniquet. Intact parathyroid hormone was assessed using the sandwich ELISA (Advia Centaur XP; SIEMENS, Germany). The source of PTH secretion was defined according to the time course of the PTH-levels during ischemia, as previously suggested by Casanova et al. [17]. In brief, a PTH decrease of more than $50 \%$ of the preischemic value (test positive) indicates the source at the tibia, whereas a PTH decrease of less than $20 \%$ of the pre-ischemic value (test negative), indicates the neck or mediastinum. A PTH decrease more than $20 \%$ and less than $50 \%$, indicates an undefined source of PTH secretion.

All patients underwent additional ultrasonography of the neck and the lower limb, electrocardiography and venous blood sampling (calcium, phosphate, alkaline phosphatase, albumin, creatinine, urea, thyroid hormones). A 99mTc-sestamibi scintigraphy was not performed as all patients were asymptomatic and showed low PTH levels.

\section{Clinical definitions}

Hypocalcemia was defined as a serum calcium level less than $2.1 \mathrm{mmol} / \mathrm{l}$ (normal range: $2.1-2.65 \mathrm{mmol} / \mathrm{l}$ ), severe hypocalcemia was defined as serum calcium less than $1.75 \mathrm{mmol} / \mathrm{l}$ with associated symptoms. Severe hypercalcemia was defined as serum calcium levels more than $3.0 \mathrm{mmol} / \mathrm{l}$. Elevated PTH was defined as PTH levels higher than $7.6 \mathrm{pmol} / \mathrm{l}$ (normal range: $1.3-7.6 \mathrm{pmol} / \mathrm{l}$ ) 
without therapeutic consequences. Recurrent HPT was defined as PTH levels higher than the Kidney Disease Outcomes Quality Initiative (KDOQI) recommended levels ca. 6 months after surgery [20]. Biochemical hypoparathyroidism was defined as insignificant/undetected PTH levels $(\mathrm{PTH} \leq 0.3 \mathrm{pmol} / \mathrm{l})$.

\section{Statistics}

Statistical analysis was performed using the $t$-test of unpaired data (Mann-Whitney $t$-test) and/or the Chisquare test with GraphPad Prism 5 (GraphPad Software Inc., La Jolla, USA). Significance was defined as $p<0.05$.

\section{Results}

At the time of examination (in average 8.2 years after surgery), 20 patients had normal PTH levels (48\%, mean $3.6 \pm 1.9 \mathrm{pmol} / \mathrm{l})$, eight patients had a mild hypoparathormonemia (19\%, mean $0.8 \pm 0.4 \mathrm{pmol} / \mathrm{l}$ ) and seven patients had a biochemical hypoparathyroidism (17\%). Among those patients with biochemical hypoparathyroidism, three had typical symptoms of hypocalcemia (7 \%), but were normocalcemic under daily substitution of calcium and vitamin D. Three patients had a recurrent HPT $(7 \%)$ according to the KDOQIrecommended PTH levels [20]. This included two patients after kidney transplantation and one patient on hemodialysis; all three patients were normocalcemic and had no typical signs and symptoms of HPT (generalized bone and muscle pain, numbness, spontaneous fractures, fatigue, mental status changes, pruritus, nephrolithiasis). The former had double the upper KDOQI-recommended PTH levels $(66.1 \mathrm{pmol} / \mathrm{l})$ and was the only patient who demonstrated a sonographic enlarged and palpable parathyroid transplant in the tibialis anterior muscle. This patient refused surgical reexploration. The need for therapeutic intervention was stated after the KDOQI criteria or symptoms causing discomfort for the patient. The dose of vitamin $\mathrm{D}$ was adjusted and the patients were referred to follow up in the nephrology department. To date there has been no need for revision.

PTH levels showed a significant decrease after surgery (preoperative $84.0 \pm 56.2 \mathrm{pmol} / \mathrm{l}$ vs. postoperative $1.4 \pm$ $2.4 \mathrm{pmol} / \mathrm{l}, p<0.0001)$.

Of the 42 patients, 25 were normocalcemic $(60 \%$, mean $2.34 \pm 0.14 \mathrm{mmol} / \mathrm{l}$ ) and 15 were slightly hypocalcemic (36 \%, mean $1.88 \pm 0.10 \mathrm{mmol} / \mathrm{l})$. One patient had a mild hypercalcemia $(2 \%, 2.71 \mathrm{mmol} / \mathrm{l})$ and one a severe hypocalcemia $(2 \%, 1.63 \mathrm{mmol} / \mathrm{l})$ with normal PTH levels and without typical symptoms.

Calcium levels also showed a significant decrease after surgery (preoperative $2.60 \pm 0.24 \mathrm{mmol} / \mathrm{l}$ vs. postoperative $2.11 \pm 0.34 \mathrm{mmol} / \mathrm{l}, p<0.0001$ ) (Tables 1 and 2).
In conclusion, TPTX with AT into tibialis anterior muscle was successful in $86 \%$ of the patients regarding PTH levels and $96 \%$ regarding calcium levels.

\section{Modified Casanova-test}

The modified Casanova-test was well tolerated by all patients with some reporting a feeling of numbness and mild pain during the ischemic time, and was discontinued in 3 patients after $10 \mathrm{~min}(7 \%)$. No other side effects were reported.

The source of PTH secretion was assessed by comparing PTH values at $15 \mathrm{~min}$ of ischemia (or at $10 \mathrm{~min}$ when the former were not available) to the pre-ischemic values. 19 patients (45\%) had a significant drop in PTH ( $\geq 50 \%)$; 11 patients ( $26 \%$ ) had a PTH drop of $\leq 20 \%$ of pre-ischemic value. The source of PTH was classified as unidentifiable (PTH drop $>20 \%$ but $<50 \%$ ) in five patients (12\%). No meaningful results were observed for seven patients with undetectable PTH levels (Fig. 1). The 50 \%-drop in PTH that classified the parathyroid autograft as the source of the PTH secretion was obtainable with $95 \%$ accuracy (in 18 of the 19 patients) after 10 min of temporary ischemic blockage.

Among the 19 patients that were positive for Casanova-test, 10 patients had normal PTH levels, as a sign for an intact graft function; four patients had higher than normal PTH levels (only two higher than the KDOQI recommended levels), indicating that the autograft was the dominant source of the elevated PTH; five patients had lower than normal PTH levels, suggesting a limited graft function. When blood flow was restored PTH levels increased up to basal values.

Among the 11 patients that were negative for Casanova-test, seven patients had normal PTH levels, as a sign for remaining parathyroid tissue or an accessory parathyroid gland in the neck/mediastinum; two patients had PTH levels higher than normal (only one patient higher than the recommended KDOQI levels) indicating the dominant source of the elevated PTH to be cervical/ mediastinal. Two patients had PTH levels lower than normal, suggesting an insufficient PTH secretion of an in-situ parathyroid gland in the neck/ mediastinum. Among these 11 negative Casanova-tests, three patients had undergone a limited parathyroidectomy of less than four glands, three patients had undergone a partial and two a total thymectomy.

In the remaining five cases (unpredictable source of PTH secretion), three patients had normal PTH levels, one patient had PTH levels higher than normal but not higher than the recommended KDOQI levels and one patient had PTH levels lower than normal. The intermediate drop of PTH indicates functioning residual cer$\mathrm{vical} /$ mediastinal glands additional to an active autograft. Among these five undefined Casanova-test results, no 
Table 1 Clinical and biochemical data of the study population

\begin{tabular}{|c|c|c|c|c|c|c|c|c|c|c|}
\hline No & $\begin{array}{l}\text { Calcium prior } \\
\text { to surgery } \\
\text { (mmol/l) }\end{array}$ & $\begin{array}{l}\text { PTH prior to } \\
\text { surgery } \\
\text { (pmol/l) }\end{array}$ & $\begin{array}{l}\text { Calcium at } \\
\text { presentation } \\
(\mathrm{mmol} / \mathrm{l})\end{array}$ & $\begin{array}{l}\text { PTH at } \\
\text { presentation } \\
\text { (pmol/l) }\end{array}$ & $\begin{array}{l}\text { Creatinine at } \\
\text { presentation } \\
(\mathrm{mg} / \mathrm{dl})\end{array}$ & $\begin{array}{l}\text { Casanova-Test } \\
\text { prediction }\end{array}$ & $\begin{array}{l}\text { PTX (number } \\
\text { of glands) }\end{array}$ & $\begin{array}{l}\text { Transcervical } \\
\text { thymectomy }\end{array}$ & $\begin{array}{l}\text { Time after } \\
\text { PTX (months) }\end{array}$ & Dialysis \\
\hline 1 & 2.40 & 147 & 1.89 & 0.9 & 1.4 & $\mathrm{~N}$ & 4 & half & 132 & No \\
\hline 2 & 2.52 & 78.2 & 1.96 & 25.2 & 10.5 & U & 4 & half & 48 & Yes \\
\hline 3 & 2.48 & 27.2 & 2.33 & 66.1 & 6.1 & P & 3 & No & 120 & Yes \\
\hline 4 & 2.81 & 143.9 & 1.93 & 4.9 & 6.5 & U & 4 & No & 96 & Yes \\
\hline 5 & 2.57 & 60.6 & 2.47 & 1.8 & 12.2 & P & 4 & No & 48 & Yes \\
\hline 6 & 2,37 & 17.5 & 1.90 & 3.3 & 8.5 & P & 4 & Yes & 84 & Yes \\
\hline 7 & 2.92 & 149.8 & 2.62 & $<0.1$ & 6.1 & M & 4 & Yes & 72 & Yes \\
\hline 8 & 2.70 & 22.4 & 1.90 & 2.3 & 0.9 & P & 4 & No & 120 & No \\
\hline 9 & 2.69 & 15.5 & 2.29 & 3.9 & 1.3 & P & 4 & No & 132 & No \\
\hline 10 & 2.73 & 41.8 & 1.89 & 1.6 & 1.4 & U & 4 & Yes & 84 & No \\
\hline 11 & 2.74 & 56 & 2.15 & 10.4 & 9.1 & N & 3 & half & 72 & Yes \\
\hline 12 & 2.44 & $63.4^{\mathrm{a}}$ & 2.21 & 2.7 & 1.2 & $\mathrm{~N}$ & 4 & No & 96 & No \\
\hline 13 & 2.84 & 78.1 & 2.36 & 2 & 6.9 & P & 4 & No & 84 & Yes \\
\hline 14 & 2.60 & 55.6 & 2.40 & 1.4 & 1.7 & P & 5 & No & 132 & No \\
\hline 15 & 2,59 & 34.7 & 2.46 & 8.7 & 1.3 & N & 4 & Yes & 84 & No \\
\hline 16 & 2.53 & 88.5 & 1.63 & 1.6 & 2.6 & P & 4 & No & 120 & No \\
\hline 17 & 2.38 & 85.5 & 1.87 & $<0,1$ & 1.9 & M & 4 & No & 132 & No \\
\hline 18 & 2.84 & 84 & 1.77 & 0.7 & 1.2 & P & 4 & No & 72 & No \\
\hline 19 & 2.48 & 48.3 & 1.87 & $<0.1$ & 1.2 & $M$ & 4 & No & 144 & No \\
\hline 20 & 2.74 & 32.5 & 2.18 & 16.3 & 2.5 & P & 4 & No & 132 & No \\
\hline 21 & 2.78 & 25.7 & 2.37 & 1.1 & 1.5 & U & 4 & No & 132 & No \\
\hline 22 & 2.45 & 145.4 & 2.34 & 5.5 & 3 & N & 3 & No & 120 & No \\
\hline 23 & 1.86 & 116.5 & 1.81 & 5.5 & 4.4 & $N$ & 4 & No & 96 & Yes \\
\hline 24 & 2.77 & 50.9 & 2.46 & $<1.0$ & 6.1 & N & 4 & No & 60 & Yes \\
\hline 25 & 2.76 & 17.4 & 2.44 & 7.7 & 1.7 & $P$ & 4 & Yes & 72 & No \\
\hline 26 & 1.93 & 129.5 & 2.47 & 3.3 & 5.9 & $\mathrm{~N}$ & 4 & No & 60 & Yes \\
\hline 27 & 2.64 & 126.3 & 2.30 & $<0.1$ & 1.3 & $M$ & 4 & No & 96 & No \\
\hline 28 & 1.96 & 139.4 & 2.10 & $<0.1$ & 2.7 & $M$ & 4 & Yes & 72 & No \\
\hline 29 & 2.57 & 33.5 & 2.36 & 1.4 & 1.3 & $P$ & 3 & Yes & 144 & No \\
\hline 30 & 2.84 & 23.8 & 2.27 & 5.1 & 1.9 & P & 2 & Yes & 72 & No \\
\hline 31 & 2.64 & $74.7^{\mathrm{a}}$ & 2.28 & 2 & 2.4 & N & 4 & No & 84 & No \\
\hline 32 & 2.71 & 130 & 2.16 & 0.1 & 2.8 & $M$ & 4 & No & 132 & No \\
\hline 33 & 2.64 & 137 & 1.95 & 6.6 & 6 & $\mathrm{~N}$ & 4 & half & 120 & Yes \\
\hline 34 & 2.79 & 16 & 2.02 & 7 & 0.9 & N & 3 & Yes & 108 & No \\
\hline 35 & 2.56 & 171 & 1.96 & 0.4 & 1.9 & P & 4 & No & 132 & No \\
\hline 36 & 2.38 & $55.2^{\mathrm{a}}$ & 1.91 & 1.2 & 1.2 & $P$ & 4 & Yes & 84 & No \\
\hline 37 & 2.66 & $18.3^{\mathrm{a}}$ & 2.71 & $<0.3$ & 2.4 & $M$ & 4 & No & 48 & No \\
\hline 38 & 2.72 & 164 & 2.15 & 15.6 & 9.1 & $P$ & 4 & No & 120 & Yes \\
\hline 39 & 2.82 & 52.1 & 2.45 & 5.5 & 1.2 & U & 4 & No & 72 & No \\
\hline 40 & 2.81 & $69.1^{\mathrm{a}}$ & 2.59 & 1.2 & 7.6 & $P$ & 4 & half & 48 & Yes \\
\hline 41 & 2.85 & 249.6 & 1.98 & 0.5 & 1.3 & P & 4 & half & 120 & No \\
\hline 42 & 2.60 & 79.7 & 2.26 & 4.4 & 1.1 & P & 4 & No & 108 & No \\
\hline
\end{tabular}

PTX parathyroidectomy, PTH intact parathyroid hormone, apatients receiving cinacalcet before surgery, $P$ positive $=$ PTH decrease of more than $50 \%$ of the pre-ischemic value, $N$ negative $=$ PTH decrease of less than $20 \%$ of the pre-ischemic value, $U$ source of PTH unpredictable $=$ PTH decrease more than $20 \%$ and less than $50 \%$ of the pre-ischemic value, $M$ Casanova-test meaningless, rej. rejection of the transplant, comb combined pancreas and kidney transplant 
Table 2 Outcome of parathyroidectomy with autotransplantation into the tibialis muscle

\begin{tabular}{|c|c|c|c|c|}
\hline & \multicolumn{4}{|c|}{ Number of patients } \\
\hline & Preoperative & Intraoperative & Postoperative & Follow up \\
\hline Hypopara (PTH $\leq 0.3 \mathrm{pmol} / \mathrm{l})$ & & 0 & 17 & 7 \\
\hline Reduced PTH (PTH >0.3 - <1.3 pmol/l) & & 2 & 8 & 8 \\
\hline Eupara (PTH 1.3-7.6 pmol/l) & & 19 & 10 & 20 \\
\hline Elevated PTH (PTH >7.6 pmol/l) & 42 & 21 & 2 & 4 \\
\hline Hyperpara according KDOQI [20] & & & & 3 \\
\hline Mean PTH (range 1.3-7.6 pmol/l) & $84.0 \pm 56.2$ & $10.6 \pm 9.1$ & $1.38 \pm 2.4$ & $5.42 \pm 10.9$ \\
\hline Mean Calcium (range 2.1-2.65 pmol/l) & $2.60 \pm 0.2$ & Nodata & $2.1 \pm 0.3$ & $2.17 \pm 0.3$ \\
\hline
\end{tabular}

PTH intact parathyroid hormone

patient had undergone a limited parathyroidectomy of less than four glands, one patient had undergone a partial and one a total thymectomy.

In conclusion, $57 \%$ of the patients had a functioning autograft according to the Casanova-test.

\section{Discussion}

Parathyroid autotransplantation has been recorded in the modern scientific literature since the beginning of the $20^{\text {th }}$ century [21]. Definitive evidence that transplanted parathyroid glands function was gathered by Wells et al. [10], who introduced the parathyroid autotransplantation into the forearm [11]; this approach such as other AT sites have been favored ever since [7, 9].

In this study, based on our traditional understanding of the key features in successful parathyroid autografting in SHPT, the tibialis anterior muscle was shown to be a novel viable site of AT of the parathyroid tissue after TPTX. Autotransplantation into the tibialis anterior muscle was successful in $86 \%$ of the patients with respect to PTH levels and $96 \%$ regarding calcium levels. $17 \%$ of the patients had postoperative biochemical hypoparathyroidism, however only $7 \%$ were symptomatic and only $2 \%$ suffered from severe hypocalcemia.
This is comparable to previous studies which have reported the rate of hypoparathyroidism in $30 \%$ after TPTX + AT, when gland was transplantated to other sites than tibialis anterior muscle [22].

As the remaining vital parathyroid tissue stays exposed to the same pathophysiological environment, graftdependent recurrent disease is a common complication after TPTX with AT, resulting in further diagnostic tests and reoperative explorations. Recurrence has been reported in 4 to $30 \%$ of patients in recent studies and 45 to $80 \%$ of patients in older studies [2, 5, 23-26], although the risk of recurrence may be minimized by selecting the appropriate tissue [3, 22, 27-29]. Tominaga et al. reported a graftdependent recurrence of $17.4 \%$ in a study cohort of 2660 patients [30]. In the current study, only $5 \%$ of the patients developed graft-dependent recurrent HPT according to the KDOQI recommended PTH levels [20], however without therapeutic consequences.

The assessment of graft function by PTH blood sampling is routinely reported in the literature [2, 4-6, 15], as is calcium levels $[2,31]$. However both methods cannot be used to assess the presence of a supernumerary gland or ectopic parathyroid tissue. Only one study has attempted to examine the actual parathyroid autograft function using

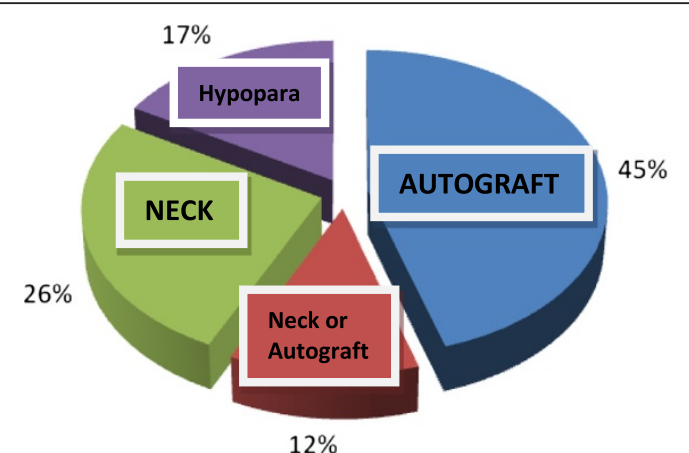

- Positive Casanova-Test (PTH-decrease $\geq 50 \%$ )

- Unpredictable CasanovaTest (PTH-decrease 20$50 \%)$

Negative Casanova-Test (PTH-decrease $\leq 20 \%$ )

- Pointless Casanova-Test $(\mathrm{PTH} \leq 0,3)$

Fig. 1 Casanova-Test and source of parathyroid hormone. Casanova-Test results show a positive Casanova-Test (PTH decrease of more than $50 \%$ of the pre-ischemic value) in 19 patients (45\%, source of PTH: autograft), a negative Casanova-Test (PTH decrease of less than $20 \%$ of the pre-ischemic value) in 11 patients (26\%, source of PTH: neck), an unpredictable Casanova-Test (PTH decrease more than $20 \%$ and less than $50 \%$ of the pre-ischemic value) in 5 patients ( $12 \%$, source of PTH unidentifiable: neck or autograft) and a pointless Casanova-Test (pre-ischemic value of PTH $\leq 0.3$ pmol/I) in 7 patients (17\%, biochemical hypoparathyroidism). PTH: intact parathyroid hormone; Hypopara: biochemical hypoparathyroidism 
the Casanova-test [19]. The autograft function may be also indirectly assessed by measuring the level of PTH in sera from the antecubital veins of the grafted and nongrafted arms, with a PTH ratio of 1.5 or greater indicating functional parathyroid tissue [14, 32]. The percentage uptake of parathyroid tissue autografts using Wells' method has been reported to range from 35 to $96 \%$ [32-35]. The percentage uptake of subcutaneously or intramuscular injected parathyroid tissue is comparable (69-90\%), however in a relatively short follow-up period [13, 14, 16]. In the current study, $57 \%$ of the patients had a functioning autograft in a long-term follow-up according to the Casanova-test; $26 \%$ of the patients had a satisfactory PTH secretion without a positive Casanova-test, indicating active remaining parathyroid tissue within the neck/mediastinum.

Besides allowing easy surgical access and simple testing, the implantation of parathyroid tissue into the lower limb could be advantageous as compared to the forearm, since in dialysis patients the anatomy of the forearms is often changed due to arteriovenous fistula (AVF) operations [36, 37]. In addition, surgical revision of the fistulas or replacement with a graft, which is necessary in cases of AVF failure, stenosis, dysfunction or occlusion, could be more complicated after autotransplantation of parathyroid tissue. Early AVF failure is common, with an incidence in the range of 20 to $60 \%[38,39]$. The tibialis anterior muscle is a relatively large and resistant muscle and therefore enables wide excisions without sacrificing vital structures, if infiltrating growth of parathyroid graft were to occur. Since dialysis patients often have a difficult vascular situation, it appears important to protect the forearm for an additional shunt revision or replacement.

Since this study was intended as pilot study, no control group was included. A further limitation of the study is that the surgical procedure wasn't standardized. Routine transcervical thymectomy was not performed. Finally, the function of the graft might be influenced by various factors, e.g. $33 \%$ of patients with insufficient PTH secretion had diabetes mellitus of which $80 \%$ revealed undetectable PTH levels $(p<0.05)$. Further studies with larger number of patient cohorts are required to confirm these data.

\section{Conclusions}

Total parathyroidectomy with AT of parathyroid tissue in the lower limb is a safe and effective therapy for renal HPT. The autograft function could be effectively assessed by means of the modified Casanova-test The advantage of preserving the forearm in CRI patients combined with the easy testing of autografts in extremities qualifies this procedure as an alternative therapy for sHPT.

\section{Abbreviations}

AT: Autotransplantation; AVF: Arteriovenous fistula; CRI: Chronic renal insufficiency; ESRD: End stage renal disease; HPT: Hyperparathyroidism; KDOQI: Kidney Disease Outcomes Quality Initiative; PTH: Intact parathyroid hormone; SCAT: Simplified Casanova autografectomy test; sHPT: secondary hyperparathyroidism; TPTX: Total parathyroidectomy; TPTX + AT: Total parathyroidectomy with autotransplantation.

\section{Competing interests}

The authors declare that they have no competing interests.

\section{Authors' contributions}

CA recruited and consulted the participants in the outpatient clinic, performed the Casanova-tests, ultrasonography and the further examinations, statistical analysis and wrote the manuscript. ML contributed to patient recruitment, performed ultrasonography and reviewed the manuscript. SS, GR and MWB reviewed and edited the manuscript. HSW as principal investigator was responsible for study design, concept, analyses and writing of the manuscript. All authors read and approved the final manuscript.

\section{Acknowledgements}

The authors would like to thank Nikos Vekris (National Metsobian Technical University of Athens) for his valuable contribution to this paper especially for his vital and selfless help in the statistical analysis of the study. The authors wish to thank Dr. Thomas Fleming, Dr. Spiros Vittas und Dr. Dimitrios

Oikonomou (Department of Medicine I and Clinical Chemistry, University of Heidelberg, Heidelberg,Germany) for their valuable comments and

suggestions to improve the quality of the manuscript.

All authors thank the patients for participation in the study.

\section{Author details}

'Department of Medicine I and Clinical Chemistry, University of Heidelberg, Im Neuenheimer Feld 410, 69120 Heidelberg, Germany. ${ }^{2}$ Department of General, Visceral and Transplantation Surgery, University of Heidelberg, Im Neuenheimer Feld 110, 69120 Heidelberg, Germany. ${ }^{3}$ Department of Internal Medicine, Kantonsspital Olten, Baslerstrasse 150, 4600 Olten, Switzerland.

Received: 19 February 2015 Accepted: 5 October 2015

Published online: 15 October 2015

\section{References}

1. Brunkhorst R. Mineral and bone disorder in chronic kidney disease. Critical appraisal of pharmacotherapy. Internist. 2014;55:334-9.

2. Pitt SC, Sippel RS, Chen H. Secondary and tertiary hyperparathyroidism, state of the art surgical management. Surg Clin North Am. 2009;89(5):1227-39.

3. Madorin C, Owen RP, Fraser WD, Pellitteri PK, Radbill B, Rinaldo A, et al. The surgical management of renal hyperparathyroidism. Eur Arch Otorhinolaryngol. 2012;269(6):1565-76.

4. Triponez F, Clark OH, Vanrenthergem Y, Evenepoel P. Surgical treatment of persistent hyperparathyroidism after renal transplantation. Ann Surg. 2008;248(1):18-30.

5. Riss P, Asari R, Scheuba C, Niederle B. Current trends in surgery for renal hyperparathyroidism (RHPT)-an international survey. Langenbeck's archives of surgery / Deutsche Gesellschaft fur Chirurgie. 2013;398(1):121-30.

6. Schneider R, Slater EP, Karakas E, Bartsch DK, Schlosser K. Initial parathyroid surgery in 606 patients with renal hyperparathyroidism. World J Surg. 2012;36(2):318-26.

7. Kiviniemi H, Vornanen T, Makela J. Prevention of complications of thyroid and parathyroid surgery. Duodecim; laaketieteellinen aikakauskirja. 2010;126(3):269-75.

8. Sciume C, Geraci G, Pisello F, Facella T, Li Volsi F, Licata A, et al. Complications in thyroid surgery: symptomatic post-operative hypoparathyroidism incidence, surgical technique, and treatment. Ann Ital Chir. 2006;77(2):115-22.

9. Jansson S, Tisell LE. Autotransplantation of diseased parathyroid glands into subcutaneous abdominal adipose tissue. Surgery. 1987;101(5):549-56.

10. Wells SA, Burdick JF, Ketcham AS, Christiansen C. Transplantation of the parathyroid glands in dogs. Biochemical, histological, and radioimmunoassay proof of function. Transplantation. 1973;15(1):179-82.

11. Wells Jr SA, Gunnells JC, Shelburne JD, Schneider AB, Sherwood LM. Transplantation of the parathyroid glands in man: clinical indications and results. Surgery. 1975;78(1):34-44. 
12. Wells Jr SA, Ross 3rd AJ, Dale JK, Gray RS. Transplantation of the parathyroid glands: current status. Surg Clin North Am. 1979;59(1):167-77.

13. Echenique-Elizondo M, Amondarain JA, Vidaur F, Olalla C, Aribe F, Garrido $A$, et al. Parathyroid subcutaneous pre-sternal transplantation after parathyroidectomy for renal hyperparathyroidism. Long-term graft function. World J Surg. 2007;31(7):1403-9.

14. Yoon JH, Nam KH, Chang HS, Chung WY, Park CS. Total parathyroidectomy and autotransplantation by the subcutaneous injection technique in secondary hyperparathyroidism. Surg Today. 2006;36(4):304-7.

15. Conzo G, Della Pietra C, Tartaglia E, Gambardella C, Mauriello C, Palazzo A, et al. Long-term function of parathyroid subcutaneous autoimplantation after presumed total parathyroidectomy in the treatment of secondary hyperparathyroidism. A Clin Retrospective Study. 2014;12 Suppl 1:S165-9.

16. Tan CC, Cheah WK, Tan CT, Rauff A. Intramuscular injection of parathyroid autografts is a viable option after total parathyroidectomy. World I Surg. 2010;34(6):1332-6.

17. Casanova D, Sarfati E, De Francisco A, Amado JA, Arias M, Dubost C. Secondary hyperparathyroidism: diagnosis of site of recurrence. World J Surg. 1991;15(4):546-9. discussion 549-550.

18. Schlosser $\mathrm{K}$, Sitter $\mathrm{H}$, Rothmund M, Zielke A. Assessing the site of recurrence in patients with secondary hyperparathyroidism by a simplified Casanova autograftectomy test. World J Surg. 2004;28(6):583-8.

19. Knudsen L, Brandi L, Daugaard H, Olgaard K, Lockwood K. Five to 10 years follow-up after total parathyroidectomy and autotransplantation of parathyroid tissue: evaluation of parathyroid function by use of ischaemic blockade manoeuvre. Scand J Clin Lab Invest. 1996;56(1):47-51.

20. National Kidney Foundation. K/DOQI clinical practice guidelines for bone metabolism and disease in chronic kidney disease. Am J Kidney Dis. 2003;42:S1.

21. Lahey. The transplantation of parathyroids in partial thyroidectomy. Surg Gynecol Obstet. 1926;62:508-9.

22. Gagne ER, Urena P, Leite-Silva S, Zingraff J, Chevalier A, Sarfati E, et al. Shortand long-term efficacy of total parathyroidectomy with immediate autografting compared with subtotal parathyroidectomy in hemodialysis patients. J Am Soc Nephrol. 1992;3(4):1008-17.

23. Dotzenrath C, Cupisti K, Goretzki E, Mondry A, Vossough A, Grabensee B, et al. Operative treatment of renal autonomous hyperparathyroidism: cause of persistent or recurrent disease in 304 patients. Langenbeck's archives of surgery/Deutsche Gesellschaft fur Chirurgie. 2003;387(9-10):348-54.

24. Hampl H, Steinmuller T, Stabell U, Klingenberg HJ, Schnoy N, Neuhaus P. Recurrent hyperparathyroidism after total parathyroidectomy and autotransplantation in patients with long-term hemodialysis. Miner Electrolyte Metab. 1991;17(4):256-60.

25. Low TH, Clark J, Gao K, Eris J, Shannon K, O'Brien C. Outcome of parathyroidectomy for patients with renal disease and hyperparathyroidism: predictors for recurrent hyperparathyroidism. ANZ J Surg. 2009;79(5):378-82.

26. Blomme RA, Blomme AM, Rinkes $I H$, Meerwaldt $R$, van der Wal MB, Valk GD, et al. Surgical strategy in patients with secondary and tertiary hyperparathyroidism. A bi-institutional series. Acta Chir Belg. 2010;110(1):35-9.

27. Niederle B, Horandner H, Roka R, Woloszczuk W. Parathyroidectomy and autotransplantation in renal hyperparathyroidism. II. Morphologic and functional studies in transplant-dependent recurrence. Der Chirurg; Zeitschrift fur alle Gebiete der operativen Medizen. 1989;60(10):671-7.

28. He Q, Zhuang D, Zheng L, Fan Z, Zhou P, Zhu J, et al. Total parathyroidectomy with trace amounts of parathyroid tissue autotransplantation as the treatment of choice for secondary hyperparathyroidism: a single-center experience. BMC Surg. 2014;14(1):26.

29. Gasparri G, Camandona M, Abbona GC, Papotti M, Jeantet A, Radice E, et al. Secondary and tertiary hyperparathyroidism: causes of recurrent disease after 446 parathyroidectomies. Ann Surg. 2001;233(1):65-9.

30. Tominaga Y, Matsuoka S, Uno N, Tsuzuki T, Hiramitsu T, Goto N, et al. Removal of autografted parathyroid tissue for recurrent renal hyperparathyroidism in hemodialysis patients. World J Surg. 2010;34(6):1312-7.

31. Sadideen HM, Taylor JD, Goldsmith DJ. Total parathyroidectomy without autotransplantation after renal transplantation for tertiary hyperparathyroidism: long-term follow-up. Int Urol Nephrol. 2012;44(1):275-81.

32. Walgenbach $\mathrm{S}$, Hommel G, Junginger T. Prospective evaluation of parathyroid graft function after total parathyroidectomy and heterotopic autotransplantation in renal hyperparathyroidism by bilateral determination of intact parathormone in cubital venous blood. World J Surg. 1998;22(1):93-7. discussion 97-98.

33. Lo CY, Tam SC. Parathyroid autotransplantation during thyroidectomy: documentation of graft function. Arch Surg. 2001;136(12):1381-5.
34. Herrera M, Grant C, van Heerden JA, Fitzpatrick LA. Parathyroid autotransplantation. Arch Surg. 1992;127(7):825-9. discussion 829-830.

35. Feldman AL, Sharaf RN, Skarulis MC, Bartlett DL, Libutti SK, Weinstein LS, et al. Results of heterotopic parathyroid autotransplantation: a 13-year experience. Surgery. 1999;126(6):1042-8.

36. Allon M, Robbin ML. Increasing arteriovenous fistulas in hemodialysis patients: problems and solutions. Kidney Int. 2002;62(4):1109-24.

37. Gibson KD, Gillen DL, Caps MT, Kohler TR, Sherrard DJ, Stehman-Breen CO. Vascular access survival and incidence of revisions: a comparison of prosthetic grafts, simple autogenous fistulas, and venous transposition fistulas from the United States Renal Data System Dialysis Morbidity and Mortality Study. J Vasc Surg. 2001;34(4):694-700.

38. Gibson KD, Caps MT, Kohler TR, Hatsukami TS, Gillen DL, Aldassy M, et al. Assessment of a policy to reduce placement of prosthetic hemodialysis access. Kidney Int. 2001;59(6):2335-45.

39. Robbin ML, Chamberlain NE, Lockhart ME, Gallichio MH, Young CJ, Deierhoi $\mathrm{MH}$, et al. Hemodialysis arteriovenous fistula maturity: US evaluation. Radiology. 2002;225(1):59-64.

\section{Submit your next manuscript to BioMed Central and take full advantage of:}

- Convenient online submission

- Thorough peer review

- No space constraints or color figure charges

- Immediate publication on acceptance

- Inclusion in PubMed, CAS, Scopus and Google Scholar

- Research which is freely available for redistribution

Submit your manuscript at www.biomedcentral.com/submit 